J. Lake Sci. (湖泊科学), 2018, 30(4): 1075-1082

DOI 10. 18307/2018. 0420

(c) 2018 by Journal of Lake Sciences

\title{
洱海湖滨区蜻蜓物种多样性与环境影响因子关系初探
}

\author{
杨国辉 ${ }^{1}$, 徐吉山 $^{1}$, 杨盛春 ${ }^{2}$, 张吉龙 $^{1}$, 张关令 $^{1}$ \\ $(1$ : 大理大学农学与生物科学学院,大理 671003) \\ (2: 大理大学药学与化学学院,大理 671003)
}

\begin{abstract}
摘 要: 为探究洱海湖滨区环境因子与蜻蜓物种多样性之间的关系,2014 年 5 月至 2017 年 5 月对洱海 10 个样点进行实 地调查, 记录植物 20 科 46 种, 共采集蜻蜓 11 科 22 属 28 种 1448 个体, 并对环境因子与蜻蜓多样性进行相关性分析. 结果 表明蜻蜓成虫多样性与植被丰富度、湿生植被覆盖度、挺水植被覆盖度和沉水植被覆盖度均呈正相关, 与浮水植物覆盖 度和人为干扰程度呈负相关; 稚虫多样性与湖底底质和水体溶解氧呈正相关, 并对结果进行了讨论. 研究结果给洱海蜻 蜓栖息地的保护及湖滨缓冲带生态修复提供了有益的参考和数据支持.
\end{abstract}

关键词: 洱海; 湖滨带; 环境因子;植被;蜻蜓; 多样性

\section{Correlationship between environmental factors and diversity of Odonata species in Erhai Lakeshore wetland}

YANG Guohui $^{1}$, XU Jishan ${ }^{1}$, YANG Shengchun ${ }^{2}$, ZHANG Jilong ${ }^{1} \&$ ZHANG Guanling ${ }^{1}$

(1: College of Agriculture and Biology Science, Dali University, Dali 671003, P.R.China)

(2: College of Pharmacy and Chemistry, Dali University, Dali 671003, P.R.China)

\begin{abstract}
In order to explore the influence of environmental factors on the species diversity of dragonflies in Lake Erhai, field studies were carried out between May 2014 to May 2017 in 10 sample sites at Lake Erhai shore. A total of 1448 Odonata samples, belonging to 28 species, 22 genera and 11 families, were reported. Meanwhile, 20 families 46 species of plants were also recorded. Correlation analysis between diversity of Odonata species (adults and larvae) and environmental factors were carried out .The results showed that the diversity of adult dragonfly were positively correlated with the vegetation richness, wetland vegetation coverage, emergent vegetation coverage, submerged aquatic vegetation coverage, whereas negatively correlated with the degree of human disturbance and floating vegetation coverage. The diversity of larvae dragonfly were positively correlated with the dissolved oxygen and sediment. The findings of the study provided practical suggestions for the protection of dragonfly habitats and the ecological restoration of lakeshore buffer strips in Lake Erhai.
\end{abstract}

Keywords: Lake Erhai; lakeshore; wetland; factor; vegetation; Odonata; biodiversity

蜻蜓目 (Odonata) 隶属于节肢动物门 (Arthropoda) 昆虫纲 ( Insecta), 是一类原始而常见的不完全变态昆 虫, 除南北两极外, 广泛分布于各种淡水环境中, 稚虫水生, 成虫多在羽化的水体附近活动, 其生活史离不开 淡水水体, 淡水环境的各种因子直接或间接的影响蜻蜓目昆虫的取食、生长、交配、产卵及发育, 从而影响蜻 蜓的种群分布和多样性变化 ${ }^{[1]}$. 近年研究结果显示: 蜻蜓目昆虫的成虫和稚虫对栖息地环境的生态响应是 一致的 ${ }^{[2-4]}$,加上蜻蜓成虫个体大, 体色艳丽, 容易识别, 又对栖息地环境因子较为敏感, 能对湿地及水-陆环 境变化做出迅速响应,所以常常作为环境的指示物种在环境监测领域应用 ${ }^{[5-9]}$.

蜻蜓目昆虫的分布与栖息地环境的关系近半个世纪以来在西方蜻蜓学界得到广泛关注,其分布与栖息 地环境的多种因素有关,如环境植被、温度和微生境及生态综合特征等 ${ }^{[10-14]}$. 栖息地环境的变化直接影响蜻

* 中国三江并流区域生物多样性协同创新中心项目、大理大学实验教学示范中心建设项目 (X-SYZX-3)、国家自然科 学基金项目(31560605) 和云南省教育厅科研项目(2015Y388) 联合资助. 2017-09-11 收稿; 2017-10-17 收修改 稿. 杨国辉(1970 ), 女, 硕士, 高级实验师; E-mail: yanggh727@ sina.com. 
蜓种群数量的改变, 从而影响蜻蜓多样性变化, 不同的研究者应用复杂统计方法和新生态理论对蜻蜓多样 性与环境因子进行了大量研究, 据不完全统计, 近 20 年来, 相关的文献就多达百余篇, 且主要集中在具有悠 久蜻蜓研究历史的国家 ${ }^{[15]}$, 如 Koparde 等 ${ }^{[16]}$ 应用多元回归分析方法对印度西高止山的蜻蜓多样性与林冠盖 度、横断面上的水域面积、海拔高度和河流等的环境变量进行分析, 结果表明蜻蜓的丰富度和多样性与林冠 盖度和水域面积呈正相关; Jeanmougin 等 ${ }^{[17]}$ 则是在评估当地环境因子后, 从景观尺度变量与蜻蜓目多样性 关系的模式下建立模型, 分析蜻蜓多样性对环境因子的响应, 指出城市内建筑物周围的池塘的蜻蜓多样性 低于郊区和城郊的池塘, 沉水植物覆盖度是影响蜻蜓多样性的关键因子, 而 Vilela 等 ${ }^{[11]}$ 应用广义线性模型 (GLM) 对巴西的棕桐沼泽地区的蜻蜓多样性与季节等环境因子的变化进行探讨,结果显示蜻蜓多样性有较 强的季节性变化, 不同种类的个体对生境选择有差异, 其物种丰富度在不同的水体间存在差异. 总之, 蜻蜓 目昆虫对生境因子的变化能做出迅速响应,其物种丰富度能客观反映当地环境状况.

我国对蜻蜓学的研究起步较晚, 目前主要集中在蜻蜓多样性调查和区系特征等方面 ${ }^{[18-21]}$, 从蜻蜓栖息生 境特征对蜻蜓多样性影响方面的研究不多 ${ }^{[22-23]}$. 本研究以洱海湖滨区为研究地点, 研究洱海湿地环境因子与 蜻蜓多样性的关系, 探讨人为干扰、湖底底质、水质、植被、植被结构与蜻蜓群落之间的关系, 分析蜻蜓目昆虫 与淡水湖泊湖滨带环境变化的响应关系, 为洱海湿地的生态修复、湿地植被选种及洱海保护提供依据.

\section{1 研究区域概况}

洱海位于云南省大理白族自治州境内, 属于澜沧江一湄公河水系. 面积为 $249.8 \mathrm{~km}^{2}$, 是云南省第二大高 原淡水湖泊. 洱海是大理市主要的生产和生活饮用水源, 被当地人称为 “母亲湖”, 也是闻名中外的“苍山洱 海” 风景区和国家重点保护自然区, 在大理地区的经济发展中起着重要作用 ${ }^{[24]} .20$ 世纪未, 洱海湖滨带遭到 严重人为破坏 (农田、房屋及鱼塘等大量侵占湖滨区), 从 2004 年开始, 大理州政府为保护洱海, 治理污染, 实施了大规模的 “双取消” (取缔机动捕捞和取消网箱养鱼) 、“三退三还” (退塘还湖、退耕还林、退房还湿 地) 、“六大行动” (环洱海生态恢复建设工程、污水处理及截污工程、面源污染治理工程、人湖河道和村落垃 圾处理综合整治工程、流域水土保持工程和流域环境管理工程) 及湖滨带生态修复等工作, 目前, 洱海治理 已经初见成效, 水质已经 6 个月保持在 II 类 ${ }^{[25-26]}$, 水生植被得到有效的恢复, 据最新调查统计洱海共记录水

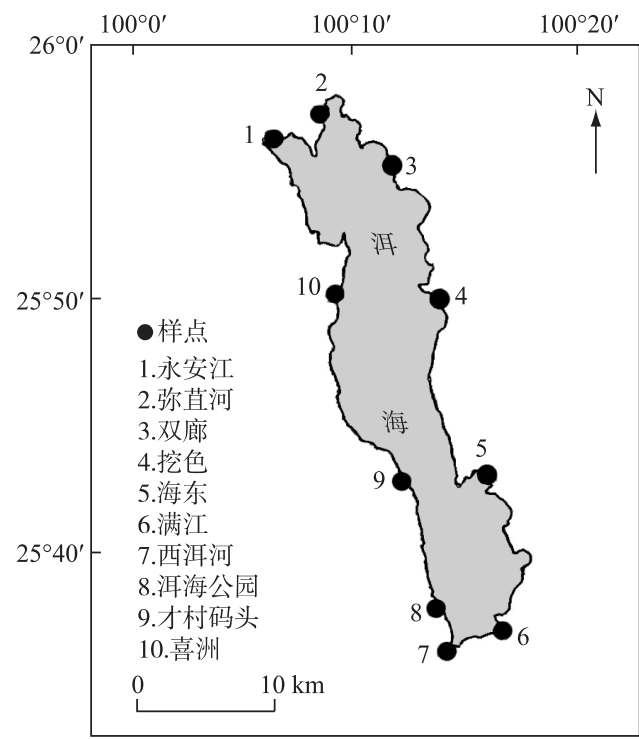

图 1 洱海湖滨带调查样点

Fig.1 Sample collection sites of the Lake Erhai lakeshore
生植物 47 科 108 属 145 种, 其中乔灌木 15 种, 湿生草本 植物 75 种, 挺水植物 15 种, 浮叶植物 7 种及沉水植物 26 种 $^{[27]}$.

\section{2 研究方法}

\section{1 调查方法}

2014-2017 年每年 5-7 月对洱海湖滨区植被、水 质等环境因子及蜻蜒进行每年 2 次调查(第 1 次在 5 月 底到 6 月初,第 2 次在 7 月中旬), 样地的选择依据湖泊 调查的基本原则 ${ }^{[28]}$, 在主要湖湾区、湖岸人群稠密区和 出人湖口, 综合考虑洱海周边的水源状况和人类活动情 况, 选择 10 个样点 (图 1).

每个样点在离湖岸 $1 \sim 10 \mathrm{~m}$, 分别设置 $5 \mathrm{~m} \times 5 \mathrm{~m}$ 样 方 $2 \sim 5$ 个, 在 $5 \mathrm{~m} \times 5 \mathrm{~m}$ 的样方中再设置 $1 \mathrm{~m} \times 1 \mathrm{~m}$ 小样 方 $2 \sim 5$ 个不等, 在小样方进行稚虫标本采集、植物调查 及水样采集, 水样带回实验室后进行水体酸碱度 $(\mathrm{pH}$, 玻璃电极法)、溶解氧浓度 ( DO, 化学探头法) 、总磷浓度 ( TP, 钿酸铵分光光度法)、总氮浓度 $(\mathrm{TN}$, 碱性过硫酸钾 消解紫外分光光度法) 及氨氮浓度 $\left(\mathrm{NH}_{3}-\mathrm{N}\right.$, 纳氏试剂 分光光度法) 的测定 ${ }^{[28]}$. 
采用限时取样法采集蜻蜓样本, 即: 在大样方内, 以 $1 \mathrm{~h}$ 为限采集蜻蜓成虫标本, 在小样方内以 $0.5 \mathrm{~h}$ 为 限,采集蜻蜓稚虫标本,稚虫用 70\%乙醇保存,成虫用三角纸袋存放.

\section{2 数据统计}

对 10 个样点, 4 年的调查数据用 Excel 统计, 除植物和蜻蜓种数外, 其余数据均取平均值 $(\mathrm{X} \pm \mathrm{SE})$.

2.2.1 人为千扰及底质数据处理 对每个样点根据年均人为干扰活动分为重度干扰、中度干扰和轻度干扰, 即年均人为干扰活动日在 $250 \mathrm{~d}$ 以上的样点划为重度干扰, $100 \sim 250 \mathrm{~d}$ 的划为中度干扰, 100 天及其以下的 划为轻度干扰 (表 1 )

观察和检测小样方的底质,底质根据颗粒从大到小依次分为砂质、泥沙和淤泥 3 种类型 (表 1).

表 1 调查样点的人为干扰及底质情况

Tab.1 Human disturbance and bottom quality of sample sites

\begin{tabular}{|c|c|c|c|c|c|c|c|c|c|c|}
\hline 样点 & 才村码头 & 洱海公园 & 西洱河 & 海东 & 满江 & 挖色 & 双廊 & 永安江 & 弥苜河 & 喜洲 \\
\hline 干扰程度 & 重度 ${ }^{+++}$ & 重度 $^{++}$ & 中度 ${ }^{++}$ & 中度 ${ }^{++}$ & 中度 $^{++}$ & 重度 $^{+++}$ & 重度 ${ }^{++}$ & 轻度 $^{+}$ & 轻度 $^{+}$ & 重度 $^{+++}$ \\
\hline 湖底底质 & 泥沙 $* *$ & 泥砂 *** & 泥砂 *** $^{*}$ & 砂质 **** & 淤泥 * & 砂质 **** & 泥砂 ** $^{\prime}$ & 泥砂 *** $^{*}$ & 泥砂 *** $^{\circ}$ & 泥砂 ** \\
\hline
\end{tabular}

“+”表示干扰强度;“*”表示湖底底质颗粒物多少.

2.2 .2 植被覆盖度及植物丰富度 对于每个样点, 选取 $5 \mathrm{~m} \times 5 \mathrm{~m}$ 样方内典型的浮水、沉水、挺水和湿生植物 群落, 其中湿生植物以株高在 $2 \mathrm{~m}$ 以下的草本和木本幼苗计算 ${ }^{[22,28]}$, 由此得到蜻蜓栖息地中的各浮水、沉水 和挺水等各层的植被覆盖度.

同时统计样地内所有 $5 \mathrm{~m} \times 5 \mathrm{~m}$ 样方中的物种组成, 计算样地植物物种的 Gleason 丰富度指数 $(D)^{[29]}$ :

$$
D=S / \ln A
$$

式中, $D$ 表示 Gleason 丰富度指数; $S$ 表示样地植物名录中所列的物种数; $A$ 表示所调查的 $5 \mathrm{~m} \times 5 \mathrm{~m}$ 样方面积 之和.

2.2.3 蜻蜓多样性数据统计 对不同样点采集的蜻蜓数量特征, 计算蜻蜓的物种 Shannon-Wiener 指数 $\left(H^{\prime}\right)^{[30]}$ :

$$
H^{\prime}=-\sum_{i=1}^{S} P_{i} \cdot \ln P_{i}
$$

式中, $S$ 表示总物种数, $P_{i}$ 表示群落中第 $i$ 个物种个体数占所有物种个体数的比例.

Kolmogorov-smirnov test 检验蜻蜓多样性及各环境因子的数据的分布是否符合正态分布,对符合正态分 布的变量采用 Pearson 相关性分析.

\section{3 结果与讨论}

\section{1 调查样地的植被特征与蜻蜓分布统计}

2014 年 5 月至 2017 年 5 月间, 在洱海湖滨区的 10 个样点共调查 $5 \mathrm{~m} \times 5 \mathrm{~m}$ 样方 65 个, $1 \mathrm{~m} \times 1 \mathrm{~m}$ 样方 104 个,采集植物 20 科 46 种,植被盖度及 Gleason 丰富度指数见表 2 , 各样点的优势种群存在差异 (表 3 ).

表 2 样地植被盖度及 Gleason 丰富度指数

Tab.2 Vegetation coverage and Gleason richness index

\begin{tabular}{cccccccc}
\hline 样地 & 小样方数 & $\begin{array}{c}\text { 浮水 } \\
\text { 植被盖度 }\end{array}$ & $\begin{array}{c}\text { 挺水 } \\
\text { 植被盖度 }\end{array}$ & $\begin{array}{c}\text { 沉水 } \\
\text { 植被盖度 }\end{array}$ & $\begin{array}{c}\text { 湿生 } \\
\text { 植被盖度 }\end{array}$ & $\begin{array}{c}\text { 物种 } \\
\text { 数目 }\end{array}$ & $\begin{array}{c}\text { Gleason } \\
\text { 丰富度指数 }\end{array}$ \\
\hline 才村码头 & 10 & 14 & 37 & 23 & 67 & 9 & 2.058 \\
洱海公园 & 10 & 6 & 30 & 5 & 40 & 6 & 1.534 \\
西洱河 & 10 & 2 & 3 & 43 & 11 & 6 & 1.534 \\
海东 & 12 & 23 & 64 & 10 & 70 & 12 & 3.067 \\
满江 & 12 & 13 & 38 & 12 & 54 & 10 & 2.107 \\
\hline
\end{tabular}




\begin{tabular}{lccccccc}
\hline 样地 & 小样方数 & $\begin{array}{c}\text { 浮水植 } \\
\text { 被盖度 }\end{array}$ & $\begin{array}{c}\text { 挺水植 } \\
\text { 被盖度 }\end{array}$ & $\begin{array}{c}\text { 沉水植 } \\
\text { 被盖度 }\end{array}$ & $\begin{array}{c}\text { 湿生植 } \\
\text { 被盖度 }\end{array}$ & $\begin{array}{c}\text { 物种 } \\
\text { 数目 }\end{array}$ & $\begin{array}{c}\text { Gleason 丰富 } \\
\text { 度指数 }\end{array}$ \\
\hline 挖色 & 10 & 3 & 0 & 64 & 23 & 8 & 2.045 \\
双廊 & 10 & 88 & 11 & 32 & 12 & 8 & 2.045 \\
永安江 & 10 & 16 & 31 & 42 & 19 & 13 & 3.323 \\
弥苗河 & 10 & 0 & 1 & 59 & 34 & 12 & 3.067 \\
喜洲 & 10 & 4 & 10 & 32 & 10 & 11 & 2.812 \\
\hline
\end{tabular}

表 3 洱海湖滨带 10 个样点植被调查统计

Tab.3 Investigation and statistics of the vegetation of 10 samples in the Erhai lakeshore

\begin{tabular}{|c|c|c|}
\hline 样地 & 植物种数 & 典型代表物种 \\
\hline 才村码头 & 9 & $\begin{array}{l}\text { 喜早莲子草 (Alternanthera philoxeroides)、菰 (Zizania caduciflora)、水杉、野慈菇 (Sagit- } \\
\text { taria trifolia var. sinensis)、垂柳 (Salix babylonica) }\end{array}$ \\
\hline 洱海公园 & 6 & $\begin{array}{l}\text { 酸模叶苶 (Polygonum lapathifolium)、丝藻 (Ulothri)、潒头舟形藻 (Navicula rhyncho- } \\
\text { cephala)、鸭舌草(Monochoria vaginalis) }\end{array}$ \\
\hline 西洱河 & 6 & $\begin{array}{l}\text { 黑藻( Hydrilla verticillata)、穂状狐尾藻 (Myriophyllum spicatum Linn)、纸莎草 (Cyperus } \\
\text { papyrus) }\end{array}$ \\
\hline 满江 & 12 & $\begin{array}{l}\text { 节节草 (Equisetum ramosissimum)、满江红 (Azolla imbricata)、茴茴蒜 ( Ranunculus } \\
\text { chinensis Bunge)、菖蒲 (Acorus calamus L)、喜旱莲子草、荇菜 (Nymphoides peltatum) }\end{array}$ \\
\hline 海东 & 10 & $\begin{array}{l}\text { 水葱 (Scirpus validus Vah)、鸭舌草、垂柳 (Salix babylonica)、水芹 (Oenanthe javanica } \\
\text { (Blume) DC)、酸模叶苶 (Polygonum lapathifolium) }\end{array}$ \\
\hline 挖色 & 8 & 金鱼藻 (Ceratophyllum demersum) 、黑藻、穂状狐尾藻、淔草 (Potamogeton crispus) \\
\hline 双廊 & 8 & 水葫芦、水葱 (Scirpus validus Vah) \\
\hline 永安江 & 13 & 菹草、芦苇 (Phragmites australis)、眼子菜( Potamogeton distinctus A. Benn)、垂柳 \\
\hline 弥苜河 & 12 & 穂状狐尾藻、眼子菜、紫茎泽兰 \\
\hline 喜洲 & 11 & 酸模叶蓼、蓝藻( Cyanobacteria)、鸭舌草 \\
\hline
\end{tabular}

共采集蜻蜓 11 科 22 属 28 种 1448 头标本 (其中稚虫 162 头, 成虫 1286 头), 样地蜻蜓种类及数量见 表 4.

表 4 样地采集蜻蜓 (成虫及稚虫) 种类、数量及多样性指数

Tab.4 Odonata( adult and nymph) species, numbers and diversity index of 10 samples

\begin{tabular}{|c|c|c|c|c|c|c|c|c|c|c|}
\hline 种类 (蜻蜓种名) & 永安江 & 弥直河 & 挖色 & $\begin{array}{l}\text { 才村 } \\
\text { 码头 }\end{array}$ & 喜洲 & $\begin{array}{l}\text { 洱海 } \\
\text { 公园 }\end{array}$ & $\begin{array}{c}\text { 西洱 } \\
\text { 河 }\end{array}$ & 满江 & 海东 & 双廊 \\
\hline 格氏圆臀大蜓 Anotogaster gregoryi & $7+2$ & $10+3$ & 0 & 0 & 0 & 0 & 0 & 0 & 0 & 0 \\
\hline 黑纹伟蜓 Anax nigrafasciatus & $7+2$ & $5+3$ & 4 & 5 & 8 & $12+2$ & $4+2$ & $14+3$ & 4 & 6 \\
\hline 碧伟蜓 Anax parthenope julius & $11+7$ & $10+3$ & $6+1$ & 9 & 8 & 12 & $5+2$ & $15+2$ & 5 & 8 \\
\hline 细腰长尾蜓 Gynacantha subinterrupta & $9+2$ & $7+1$ & 4 & 5 & 8 & 0 & 0 & 0 & 0 & 0 \\
\hline 马奇异春蜓 Anisogomphus maacki & 0 & 4 & 0 & 0 & 0 & 0 & 0 & 0 & 0 & 0 \\
\hline 莫弓蜻 Macromia moore & $7+1$ & $6+1$ & 0 & 4 & 3 & 7 & 0 & 7 & 0 & 0 \\
\hline 闪蓝丽大蜻 Epophthalmia elegans & 2 & 3 & 0 & 0 & 0 & 0 & 0 & 0 & 0 & 0 \\
\hline 半伪蜻 Hemicordulia edai & 0 & 0 & $8+3$ & 7 & 4 & 7 & 7 & 9 & 7 & 8 \\
\hline 黄翅蜻 Brachythemis contaminata & $9+3$ & $13+2$ & $11+2$ & $7+3$ & $8+2$ & $11+4$ & 7 & $13+2$ & $4+2$ & $8+3$ \\
\hline 红蜻 Crocothemis servilia & $8+2$ & 8 & $6+1$ & $5+2$ & $8+5$ & $6+2$ & $6+1$ & $10+1$ & $9+3$ & 12 \\
\hline 斑蓝小蜻 Diplacodes nebulosa & 7 & 8 & 0 & 0 & 0 & 0 & 0 & 0 & 0 & 0 \\
\hline
\end{tabular}


续表 4

\begin{tabular}{|c|c|c|c|c|c|c|c|c|c|c|}
\hline 种类 (蜻蜓种名) & 永安江 & 弥直河 & 挖色 & $\begin{array}{l}\text { 才村 } \\
\text { 码头 }\end{array}$ & 喜洲 & $\begin{array}{l}\text { 洱海 } \\
\text { 公园 }\end{array}$ & $\begin{array}{c}\text { 西洱 } \\
\text { 河 }\end{array}$ & 满江 & 海东 & 双廊 \\
\hline 白尾灰蜻 Orthetrum albistylum & 0 & 0 & 6 & $9+2$ & $7+2$ & 7 & $5+2$ & 8 & 4 & 6 \\
\hline 灰蜻属一种 Orthetrum sp. & 0 & 5 & 0 & 9 & 7 & 0 & 0 & 0 & 0 & 0 \\
\hline 狭腹灰蜻 Orthetrum sabina & $12+1$ & $11+1$ & 6 & 9 & 10 & 7 & 7 & 6 & 7 & 8 \\
\hline 鼎异色灰蜻 Orthetrum triangulare & 10 & $8+2$ & 7 & $7+2$ & $6+3$ & 0 & 0 & 0 & 6 & 9 \\
\hline 赤褐灰蜻 Orthetrum neglectum & 4 & 6 & 6 & 9 & 8 & 6 & 4 & 8 & 8 & 7 \\
\hline 黄蜻 Pantala flavescens & 5 & 0 & $8+1$ & 8 & 10 & $9+3$ & $7+5$ & $9+2$ & $8+3$ & 5 \\
\hline 方氏赤蜻 Sympetrum fonscolombei & 1 & 0 & 0 & 0 & 0 & 0 & 1 & 0 & 5 & 6 \\
\hline 旭光赤蜻 Sympetrum hypomelas & $9+4$ & $7+3$ & 0 & 7 & 8 & $5+3$ & 4 & $7+5$ & 0 & 0 \\
\hline 昂卡闪色蟌 Caliphaea angka & 7 & 6 & 0 & 0 & 0 & 0 & 0 & 0 & 0 & 0 \\
\hline 黄脊圣鼻蟌 Aristocypha fenestrella & 4 & 3 & 0 & 0 & 0 & 0 & 0 & 0 & 0 & 0 \\
\hline 长尾黄蟌 Ceriagrion fallax & 1 & 0 & 0 & $4+1$ & 8 & 4 & 5 & 8 & 7 & 6 \\
\hline 蓝尾狭翅蟌 Aciagrion olympicum & 9 & 8 & $6+2$ & 7 & 10 & 12 & $8+2$ & 10 & 10 & 8 \\
\hline 赤斑异痣蟌 Ischnura mildredae & $7+1$ & 6 & 4 & $8+2$ & $7+1$ & 7 & 8 & 8 & $7+3$ & $6+2$ \\
\hline 蓝面尾蜴 Paracercion melanotum & $10+2$ & $8+1$ & 0 & $7+1$ & 8 & 8 & 8 & $9+4$ & 0 & 0 \\
\hline 朱腹丽扇蟌 Calicnemia eximia & 7 & 12 & 0 & 2 & 0 & 0 & 0 & 0 & 0 & 0 \\
\hline 细腹绿综蟌 Megalestes micans & 8 & 9 & 0 & 4 & 10 & 0 & 2 & 0 & 0 & 0 \\
\hline 黄面赫丝蟌 Indolestes assamica & $9+1$ & 8 & 0 & $8+2$ & 10 & 6 & 7 & 8 & 0 & 0 \\
\hline 蜻蚯成虫种数 & 24 & 23 & 13 & 21 & 20 & 16 & 17 & 16 & 14 & 7 \\
\hline 蜻蜓成虫数量 & 170 & 171 & 82 & 140 & 156 & 126 & 95 & 149 & 91 & 103 \\
\hline 蜻蚯成虫多样性指数 & 3.05 & 3.08 & 2.52 & 2.99 & 2.96 & 2.72 & 2.75 & 2.73 & 2.59 & 2.61 \\
\hline 蜻蜓稚虫种数 & 12 & 10 & 5 & 8 & 5 & 5 & 8 & 7 & 4 & 2 \\
\hline 蜻蜓稚虫数量 & 28 & 21 & 10 & 18 & 14 & 14 & 20 & 19 & 11 & 5 \\
\hline 蜻蚯稚虫多样性指数 & 2.38 & 2.30 & 1.88 & 2.13 & 1.43 & 1.57 & 1.96 & 1.83 & 1.37 & 0.67 \\
\hline
\end{tabular}

“+”表示有稚虫, “+”后面数字表示稚虫数量.

\section{2 湖底底质和水质因子与蜻蜓稚虫多样性的相关性分析}

调查样点的蜻蜓稚虫多样性与湖底底质 $(r=0.39, P=0.039)$ 及溶解氧 $(r=0.54, P=0.024)$ 均呈正相关, 而与其他水质因子均呈负相关 (表 5 ).

表 5 湖底底质、干扰程度及水质情况与蜻蜓稚虫多样性

Tab.5 The lake bottom, interference degree, quality of water and diversity of Odonata nymphs correlation analysis

\begin{tabular}{cccccc}
\hline & 湖底底质 & DO & TP & TN & $\mathrm{NH}_{3}-\mathrm{N}^{-}$ \\
\hline 湖底底质 & 1 & & & & \\
DO & 0.40 & 1 & & & \\
$\mathrm{TP}$ & -0.29 & -0.75 & 1 & 1 & 1 \\
$\mathrm{TN}$ & -0.50 & -0.55 & 0.07 & 0.76 & -0.07 \\
$\mathrm{NH}_{3}-\mathrm{N}$ & -0.84 & -0.64 & 0.37 & -0.17 & \\
蜻蜓稚虫多样性 & 0.39 & $0.54^{*}$ & -0.37 & & \\
\hline
\end{tabular}

* 表示在 0.05 水平 (双侧) 上显著相关.

\section{3 植物与蜻蜓成虫相关性分析}

蜻蜓成虫多样性指数与植物种数 $(r=0.623, P=0.067)$ 和植被丰富度指数 $(r=0.498, P=0.028)$ 均呈正相 关, 蜻蜓种数及植物丰富度 $(r=0.513, P=0.021)$ 也呈正相关. 


\section{4 不同植被盖度、人为干扰与蜻蜓成虫多样性相关性分析}

蜻蜓成虫多样性与人为干扰呈正相关 $(r=0.74, P=0.013)$; 与湿生植被盖度 $(r=0.62, P=0.055)$ 、挺水 植被盖度 $(r=0.61, P=0.05)$ 和沉水植被盖度 $(r=0.59, P=0.07)$ 均呈正相关, 与浮水植被盖度呈负相关 $(r=$ $-0.29, P=0.040)$; 湿生植被盖度与挺水植被盖度 $(r=0.85, P=0.038)$ 和沉水植被盖度 $(r=0.79, P=0.031)$ 均呈正相关 (表 6).

\section{表 6 植被盖度与蜻蜓成虫多样性的相关性分析}

Tab.6 Correlation analysis of vegetation coverage and diversity of dragonfly adults

\begin{tabular}{|c|c|c|c|c|c|c|}
\hline & $\begin{array}{c}\text { 蜻蜓成虫 } \\
\text { 多样性 }\end{array}$ & $\begin{array}{c}\text { 浮水植被 } \\
\text { 盖度 }\end{array}$ & $\begin{array}{c}\text { 挺水植被 } \\
\text { 盖度 }\end{array}$ & $\begin{array}{c}\text { 沉水植被 } \\
\text { 盖度 }\end{array}$ & $\begin{array}{c}\text { 湿生植被 } \\
\text { 盖度 }\end{array}$ & $\begin{array}{l}\text { 干扰 } \\
\text { 程度 }\end{array}$ \\
\hline 蜻蜓成虫多样性 & 1 & & & & & \\
\hline 浮水植被盖度 & -0.29 & 1 & & & & \\
\hline 挺水植被盖度 & 0.61 & -0.27 & 1 & & & \\
\hline 沉水植被盖度 & 0.59 & -0.06 & $0.76^{*}$ & 1 & & \\
\hline 湿生植被盖度 & 0.62 & -0.23 & $0.85^{*}$ & $0.79^{*}$ & 1 & \\
\hline 干扰程度 & $0.74^{*}$ & -0.19 & $0.84^{*}$ & $0.85^{*}$ & $0.83^{*}$ & 1 \\
\hline
\end{tabular}

*表示在 0.05 水平 (双侧) 上显著相关.

\section{4 讨论}

湖滨带是水陆生态交错的过渡带, 是湖泊的天然屏障, 属于地球上最脆弱的湿地生态系统之一 ${ }^{[30-31]}$. 从 4 年的调查结果看, 主要的挺水和沉水植物种群数量有明显变化, 其中不乏大量引入种如紫茎泽兰 $(E u-$ patorium adenophora) 、水葫芦 (Eichhornia crassipes)、三角梅 (Bougainvillea spectabilis) 和水杉 (Metasequoia glypotroboides) 等, 蜻蜓成虫多样性与植物丰富度呈正相关, 洱海湖滨带植被的演替影响着蜻蜓成虫多样性 变化, 植被多样性不仅反应了蜻蜓栖息环境的复杂程度, 还为蜻蜓提供了取食、交配等活动的场所, 湿地植 被丰富度高的生境中蜻蜓的种类和数量也较多, 这与已有的研究结果一致 ${ }^{[10-11,22]}$. 从不同植被的盖度来看, 蜻蜓成虫多样性与湿生植被盖度、挺水植被盖度和沉水植被盖度均呈正相关, 与浮水植被盖度呈负相关, 这 与王辰等 ${ }^{[22]}$ 对北京地区湿地植被对蜻蜓生态分布研究有差异, 这是否与洱海湖滨带浮水植物种类和植物群 落结构不稳定有关, 还有待于进一步研究.

研究结果还显示重度人为干扰导致蜻蜓成虫多样性降低, 两者之间具有较高的负相关性, 一般认为人 为干扰将改变生态系统内部及其与外界间的能量交换与流动, 从而改变动物栖息地的环境因子, 降低物种 多样性 ${ }^{[32-33]}$, 这与本研究的结果一致; 蜻蜓目昆虫的生活史离不开淡水水体, 水体环境是蜻蜓稚虫赖以生存 的场所, 尽管不同的类群对水体因子要求不尽相同, 但蜻蜓总体趋势偏好选择水质好的淡水环境 ${ }^{[1,3]}$, 这一 结果在本研究中也得到验证, 即水质因子中除溶解氧浓度与蜻蜓稚虫多样性呈正相关外, 与总磷、总氮和氨 氮浓度均呈负相关. 湖底底质也一定程度的影响蜻蚯的群落变化, 这可能是底质颗粒大存在一定的空隙, 能 为蜻蜓的卵的发育及稚虫提供较好的搵伏环境有关.

总之,洱海湖滨带受人为干扰较为严重, 其湖滨带植被及水体等环境也经历多次演替 ${ }^{[34-36]}$, 湖滨带的环 境因子直接影响蜻蜓分布, 环境因子的改变势必对蜻蜓物种多样性产生影响, 所以在城市规划和建设中,应 减少对洱海自然湿地的破坏和人为干扰, 减少外来人侵种, 保证湿地植被的多样性及群落结构的完整性,在 对湖滨带进行生境修复时应综合考虑当地植被结构和植被种类合理选种.

\section{5 参考文献}

[ 1 ] Corbet PS ed. Dragonflies behavior and ecology of Odonata. New York: Cornell University Press, 1999.

[ 2 ] Amico D, Darblade F, Avignon S et al. Odonates as indicators of shallow lake restoration by liming: Comparing adult and larval responses. Restoration Ecology, 2004, 12: 439-446. 
[ 3 ] Oertli B. The use of dragonflies in the assessment and monitoring of aquatic habitats. In: Cordoba-Aguilar A ed. Model organisms for ecological and evolutionary research. Oxford: Oxford University Press, 2008: 79-95.

[ 4 ] Valente-Neto F, Oliveira RF, Rodrigues ME et al. Artificial ponds increase local dragonfly diversity in a global biodiversity hot spot. Biodiversity and Conservation, 2016, 25: 1921-1935.

[ 5 ] Watson JAL, Arthinfgtion AH, Conrick DL. Effects of sewage effluent on dragonflies (Odonata) of Bulimba Creek, Brisbane. Aust J Marine Freshw Res, 1982, 33(3) : 517-528.

[ 6 ] Clark TE, Samways MJ. Dragonflies (Odonata) as indicators of biotype quality in the Kruger National Park, South Africa. J Appl Ecol, 1996, 33: 1001-1012.

[ 7 ] Chovanec A, Waringer J, Raab R et al. Lateral connectivity of a fragmented large rive system: Assessment on amacroscale by dragonfly surveys (Insecta: Odonata). Aquatic Conservation: Marine and Freshwater Ecosystems, 2004, 14: 163-178.

[ 8 ] Chovanec A, Schindler M, Waringer J et al. The dragonfly association index (insecta: odonata) - A tool for the type-specific assessment of lowland rivers. River Research and Applications, 2015, 5: 627-638.

[ 9 ] Yu X, Bu WJ, Zhu L. Research advances in eco-environment assessment using dragonfly as a bioindicator. Chinese Journal of Ecology, 2012, 31(6): 1585-1590. [于昕, 卜文俊, 朱琳. 应用蜻蜓目昆虫进行生态环境评价的研究进展. 生态 学杂志, 2012, 31(6): 1585-1590.]

[10] Dolny A, Harabis F, Mizicová H. Home range, movement, and distribuition patterns of the threatened dragonfly Sympetrum depressiusculum (Odonata: Libellulidae): A thousand times greater territory to protect? PLoS One, 2014, 9: 1-10.

[11] Vilela DS, Ferreira RG, Del-Claro K. The odonata community of a brazilian vereda: seasonal patterns, species diversity and rarity in a palm swamp environment. Biosci J Uberlândia, 2016, 32: 486-495.

[12] Sahlen G, Ekestubb K. Identification of dragonfiies (Odonata) as indicators of general species richness inboreal forest lakes. Biodiversity and Conservation, 2001, 10: 673-690.

[13] Monteiro Júnior CS, Couceiro SRM, Hamada N et al. Effect of vegetation removal for road building on richness and composition of Odonata communities in Amazonia, Brazil. International Journal of Odonatology, 2013, 16: 135-144.

[14] Dutra S, De Marco, Jr P. Bionomic differences in Odonates and their influence on the efficiency of indicator species of environmental quality. Ecol Ind, 2014, 49: 132-142.

[15] Miguela TB, Calvãob LB, Vitalc MVC et al. A scientometric study of the order Odonata with special attention to Brazil. International Journal of Odonatology, 2017, (1) : 1-16.

[16] Koparde P, Mhaske P, Patwardhan A. Habitat correlates of Odonata species diversity in the northern Western Ghats, India. Odonatologica, 2015, 44: 21-43.

[17] Jeanmougin M, Leprieur F, Loïs G et al. Fine-scale urbanization affects Odonata species diversity in ponds of a megacity (Paris, France). Acta Oecologica, 2014, 59(8): 26-34.

[18] Yang GH, Mao BY, Xu JS et al. A preliminary report on the investgation of dragonflies from cangshan national natitureonal nature reserve of Yunnan. Journal of Dali University, 2008, 7(2):9-11. [杨国辉, 毛本勇, 徐吉山等. 苍山国家自然 保护区蜻蜓调查初报. 大理学院学报, 2008, 7(2): 9-11.]

[19] Yu WY, Li ZH, Luo QH et al. Study on fauna and diversity of Odonata in Maolan area of Guizhou. Sichuan Journal of Zoology, 2012, 31(5): 828-833. [虞蔚岩, 李朝晖, 罗庆怀等. 贵州茂兰自然保护区蜻蜓多样性初步研究. 四川动 物, 2012, 31(5): 828-833.]

[20] Li QJ, Huang HT, Li ZR et al. Study on diversity and fauna of Odonata in Macao. Guandong Agricultural Sciences, 2015, 24: 157-161. [李秋剑, 黄海涛, 李志锐等. 澳门蜻蜓目昆虫的多样性和区系研究. 广东农业科学, 2015, 24: 157-161.]

[21] Xu L, Chen LP, Wang ZZ et al. Seasonal changes in fluctuations in temperature and humidity on the quantity and type of dragonfly fluctuations effects. Hubei Agricultural Sciences, 2016, 55(3): 643-646. [徐璐, 陈玲棚, 王真祯等. 温湿度 的季节性变化对蜻蜓目昆虫数量和种类的影响. 湖北农业科学, 2016, 55(3): 643-646.]

[22] Wang C, Gao XY, Liu Y et al. Effects of wetland vegetations on ecological distribution of Odonata species in Beijing, China. Acta Ecologica Sinica, 2007, 27(2) : 515-525. [王辰, 高新宇, 刘阳等. 湿地植被对北京蜻蜓生态分布的影响. 北京师范大学生态学报, 2007, 27(2) : 515-525.]

[23] Saiyi-la-mu-gu-li a-bu-du-mu-sai. Assessing the effects of river ecological restoration based on a biological (dragonfly) [Dissertation]. Changchu: Northeast Normal University, 2014: 1-43. [萨依拉姆姑丽·阿布杜木萨. 基于指示生物(蜻 
蜓) 的河流生态修复效果评价研究 [学位论文]. 长春: 东北师范大学, 2014: 1-43.]

[24] People's Government of Bai Autonomous Prefecture in Yunnan, Dali Green River basin construction and water pollution control program in Erhai, 2010. [云南大理白族自治州人民政府. 洱海绿色流域建设与水污染防治规划, 2010.]

[25] Cai YF, Zhang HC, Chen GJ et al. The research status and problems on ecology and environment of Lake Erhai. Advances in Geosciences, 2013, (6) : 245. [ 蔡燕凤, 张虎才, 陈光杰等. 洱海生态环境研究现状及存在问题. 地球科学前沿, 2013, (6): 245.]

[26] Zhang HY, Cai QH, Tang T et al. Comprehensive assessment and comparison of lakes' ecosystem health in Erhai watershed. China Environmental Science, 2012, 32(4): 715-720. [张红叶, 蔡庆华, 唐涛等. 洱海流域湖泊生态系统健康 综合评价与比较. 中国环境科学, 2012, 32(4): 715-720.]

[27] Li EH, Wang XL, Cai XB et al. Features of aquatic vegetation and the influence factors in Erhai lakeshore wetland. J Lake $S c i, 2011,23(5)$ : 728-746. DOI: 10.18307/2011.0511. [厉恩华, 王学雷, 蔡晓斌等. 洱海湖滨带植被特征及其影 响因素分析. 湖泊科学, $2011,23(5): 728-746$.

[28] Nanjing Institute of Geography and Limnology, Chinese Academy of Sciences ed. Technical regulations for lake survey. Beijing: Science Press, 2015. [中国科学院南京地理与湖泊研究所. 湖泊调查技术规程. 北京: 科学出版社, 2015.]

[29] Li Q, Xu C et al eds. Wetland plants. Guangzhou: South Daily Press, 2010. [李强, 徐春等. 湿地植物. 广州: 南方日 报出版社, 2010.]

[30] Hu XZ. Study on restoration of aquatic vegetation in Lake Erhai. Beijing: Chinese Research Academy of Environmental Sciences, 1999. [胡小贞. 云南洱海水生植被恢复研究. 北京: 中国环境科学研究院, 1999.]

[31] Yin CQ. The ecological function, protection and utilization of land/inland water ecotones. Acta Ecologica Sinica, 1995,15 (3) : 331-335. [尹澄清. 内陆水一陆交错带的生态功能及其保护与开发前景. 生态学报, 1995, 15(3) : 331-335.]

[32] Yang LJ, Zhang DD. Diversity of moth communities and variation along artificial disturbance gradient in Mount Jinggangshan National Nature Reserve, China. Journal of Environmental Entomology, 2014, 36(5): 679-686. [杨立军, 张丹丹. 井冈山自然保护区蛾类多样性及人为干扰的影响. 环境昆虫学报, 2014, 36(5): 679-686.]

[33] Yao SG, Chen DL, Zhang SL. Effects of human interference on the arthropods diversity and the forests health of masson pine stands. Journal of Fujian College of Forestry, 2011, 31(3) : 262-266. [姚绍刚, 陈巅立, 张思禄等. 人为干扰对 马尾松林节肢动物多样性及其林分健康的影响. 福建林业学报, 2011, 31(3) : 262-266.]

[34] Fu H, Yuan GX, Cao T et al. Succession of submerged macrophyte communities in relation to environmental change in Lake Erhai over the past 50 years. J Lake Sci, 2013, 25(6) : 854-861. DOI:10.18307/2013.0609. [符辉, 袁桂香, 曹 特等. 洱海近 50 年来沉水植被演替及其主要驱动要素. 湖泊科学, 2013, 25(6):854-861.]

[35] Su L, Huang JH, Wu M. Insect diversity in wetland vegetation succession: A review. Chinese Journal of Ecology, 2012, 31(6) : 1577-1584. [苏兰, 黄俊浩, 吴明等. 湿地植被演替过程中昆虫多样性变化研究进展. 生态学杂志, 2012, 31(6): 1577-1584.]

[36] Zhu H, Peng YY, Wang DL et al. Effects of plant on insect diversity: A review. Chinese Journal of Ecology, 2008, 27 (12) : 2215-2221. [ 朱慧, 彭媛媛, 王德利. 植物对昆虫多样性的影响. 生态学杂志, 2008, 27 (12): 2215-2221.] 